\title{
Conjugation of the Recombinant Third Domain of Human Alpha-fetoprotein with Doxorubicin Using Poly(amidoamine) Dendrimers and Study of Its Cytotoxic Activity
}

\author{
S. I. Kisil ${ }^{1}$, V. A. Chernikov ${ }^{2}$, M. I. Danilevskiy ${ }^{2}$, L. V. Savvateeva ${ }^{3}$, N. V. Gorokhovets ${ }^{4}$ \\ ${ }^{1}$ Biochemistry department, I.M. Sechenov First Moscow State Medical University, Moscow, Russia \\ ${ }^{2}$ Research Institute of Uronephrology and Reproductive Health Care of the I. M. Sechenov First MSMUk, Moscow, Russia \\ ${ }^{3}$ National Research Centre "Kurchatov Institute", Moscow, Russia \\ ${ }^{4}$ Research Institute of Molecular Medicine of the I. M. Sechenov First MSMU, Moscow, Russia \\ Email: ksi-5826@mail.ru \\ Received 2012
}

\begin{abstract}
The recombinant third domain of alpha-fetoprotein (AFP3D) is one of the promising vectors for targeted delivery of anticancer drugs to tumor cells. AFP3D-based conjugates with various anti-tumor agents have shown specific anti-tumor activity. The content of anti-tumor drugs in the preparation could be increased by including dendrimers - highly branched nanoparticles - into a targeted delivery system. In this study, we synthesized the AFP3D conjugate with doxorubicin-loaded poly(amidoamine) (PAMAM) dendrimer nanoparticles and investigated its cytotoxic activity.
\end{abstract}

Keywords: Alpha-fetoprotein; Dendrimer; Doxorubicin; Targeted Delivery

\section{Introduction}

Cancer targeted therapy represents one of the most rapidly developing areas in pre-clinical and clinical cancer research. The recombinant third domain of alpha-fetoprotein (AFP3D) is one of the promising vectors for targeted delivery of anticancer drugs to tumor cells. Alpha-fetoprotein (AFP) is a glycoprotein, found in embryonic and fetal serum [1,2]. The biological role of AFP is not fully elucidated, but the protein has an affinity for certain types of tumors, is a carrier of hydrophobic molecules and metabolites in the body [3]. The ability to accumulate in tumors makes AFP a potential vector for the creation of targeted anticancer drugs. Isolation of AFP from fetal material is associated with significant complications [4], and therefore a recombinant AFP and the third functional domain of AFP were expressed in E. coli $[5,6]$.

Constructs, based on AFP3D, conjugated with various anti-tumor agents, have shown specific anti-tumor activity [7], but the content of the cytotoxic substance in these preparations was too low, as a rule. While carrying out the conjugation of protein with an antibiotic directly, the recommended degree of conjugation is no more than 1.5-2 molecules of antibiotic per molecule of protein, otherwise the conformation of the protein molecule changes considerably and won't be recognized by a specific receptor. However, to heighten treatment effectiveness the proportion of the antibiotic must be increased. This can be done by including dendrimers - highly branched nanoparticles - into a targeted delivery system. The accession of antibiotic molecules to the protein through the dendrimer particle can significantly increase the content of antibiotic drug without affecting the protein itself.

\section{Materials and Methods}

Reagents: Doxorubicin hydrochloride was purchased from
Ferein (Russia). Dendrimer PAMAM G-3.5 was purchased from Sigma-Aldrich (USA).

Bacterial strain: E.coli BL21 (DE3) strain containing plasmid pAFP28D3 was kindly provided by the Institute of Molecular Medicine, I. M. Sechenov First Moscow State Medical University.

\subsection{Expression of AFP3D in E. Coli.}

E. coli strain- producer of recombinant AFP3D- was grown in LB medium with kanamycin $(50 \mu \mathrm{g} / \mathrm{mL})$. Bacterial cells were grown in aerobic conditions for 12 hours at $37^{\circ} \mathrm{C}$ in a thermostatic shaker "Orbi-safe" ("Sanjo", UK), then diluted 50 times and raised for 3-4 hours until the A600 reached 0.6-0.8 units. Synthesis of recombinant protein was induced by adding isopropylthio- $\beta$-galactoside (IPTG; $1 \mathrm{mM}$ ) and the culture was left for 3 hours at $37^{\circ} \mathrm{C}$ with shaking. Cells were harvested by centrifugation $\left(10,000 \mathrm{~g}, 15 \mathrm{~min},+4^{\circ} \mathrm{C}\right)$ and cell pellet was stored at $-30^{\circ} \mathrm{C}$. Production of recombinant protein was tested using polyacrylamide gel electrophoresis (PAGE) under denaturing conditions.

\subsection{Isolation, Refolding and Purification of Recombinant AFP3D}

Biomass from $150 \mathrm{ml}$ of culture medium was dissolved in 10 $\mathrm{ml}$ of buffer A (0.02 M Tris- $\mathrm{HCl}, 0.3 \mathrm{M} \mathrm{NaCl}, 2 \mathrm{mM}$ PMSF (phenylmethanesulfonylfluoride), $\mathrm{pH}$ 8.0) and homogenized by ultrasound disintegrator High Intensity Ultrasonic Processor 750 Watt Series (“Cole Parmer”, USA) for 1 min on ice. Then the suspension was harvested by centrifugation for $10 \mathrm{~min}$ $\left(12,000 \mathrm{~g},+4^{\circ} \mathrm{C}\right)$. The cell pellet was resuspended in $5 \mathrm{~mL}$ of 
buffer A and centrifuged under the above conditions to clean the inclusion bodies. This procedure was repeated five times. Then the inclusion bodies were dissolved in $4 \mathrm{~mL}$ of buffer $\mathrm{B}$ (0.1 M Tris-HCl, 6M guanidine chloride, $\mathrm{pH}$ 8.0), sonicated to solubilize proteins and centrifuged for $30 \mathrm{~min}\left(12000 \mathrm{~g},+4^{\circ} \mathrm{C}\right)$. The supernatant was applied to the column with $2 \mathrm{~mL}$ iminodiacetate-Sepharose saturated with nickel ions (Chelating Sepharose $\mathrm{Cl}-6 \mathrm{~B}$ ) and equilibrated with buffer B. The column was washed with $10 \mathrm{~mL}$ of buffer $\mathrm{B}$, and then proteins were eluted with $6 \mathrm{~mL}$ of buffer $\mathrm{C}(0.05 \mathrm{M}$ Tris- $\mathrm{HCl}, 6 \mathrm{M}$ urea, $0.4 \mathrm{M} \mathrm{NaCl}$ and $0.3 \mathrm{M}$ imidazole, $\mathrm{pH}$ 8.0). $\beta$-Mercaptoethanol (0.1 M) was added to the eluate with subsequent incubation for 1 hour at room temperature with stirring. Solution of the reduced protein was added dropwise to $60 \mathrm{~mL}$ of buffer $\mathrm{E}$ (0.1 M Tris-HCl, 0.5 $\mathrm{M} \mathrm{NaCl,} 2 \mathrm{mM}$ EDTA, $0.4 \mathrm{M}$ arginine, $\mathrm{pH}$ 8.0), chilled to $+4^{\circ} \mathrm{C}$. After incubation for 24 hours at $+4^{\circ} \mathrm{C}$ with stirring, solution was dialyzed against $3 \mathrm{~L}$ of buffer $\mathrm{F}$ ( 0.05 Tris-HCl, 0.15 $\mathrm{NaCl}, 2 \mathrm{mM}$ EDTA, pH 8.0), then against $3 \mathrm{~L}$ of buffer $\mathrm{G}$ (0.01 M Tris-HCl, $0.15 \mathrm{M} \mathrm{NaCl}, \mathrm{pH}$ 8.0) for 24 hours each. The dialyzed protein was concentrated on the cell membrane Amicon PM-10 ("Millipore", USA) to $400 \mathrm{~mL}$. The concentrate was fractionated on a column Toyopearl TM DEAE ("Tosoh Bioscience LLC") by elution with a gradient of 0-0.5 $\mathrm{M} \mathrm{NaCl}$ with a flow rate of $1 \mathrm{~mL} / \mathrm{min}$ and detection at $280 \mathrm{~nm}$. The target fraction (monomer) was concentrated on the cell Amicon (PM-10) to $1.5 \mathrm{~mL}$ and stored at $-70^{\circ} \mathrm{C}$. Protein concentration was determined by the BCA assay (Bicinchoninic Acid Kit, Sigma).

\subsection{Investigation of AFP3D Binding and Endocytosis by Flow Cytofluorometry}

1) Synthesis of fluorescein isothiocyanate (FITC)-labeled AFP3D: $6.5 \mu \mathrm{L}$ (4-fold molar excess) of FITC solution in DMSO (dimethyl sulfoxide) $(10 \mathrm{mg} / \mathrm{mL})$ was added to AFP3D solution (1 mg in $0.1 \mathrm{M}$ bicarbonate buffer, $\mathrm{pH}$ 8.5) and the mixture was stirred in the dark for 1 hour at room temperature, then for 18 hours at $+4^{\circ} \mathrm{C}$. FITC-labeled protein was applied to a column with Sephadex G-25 equilibrated with phosphate buffered saline (PBS), $\mathrm{pH}$ 7.4. Protein fraction was eluted with the same buffer at a flow rate of $1 \mathrm{~mL} / \mathrm{min}$ and detection at 280 $\mathrm{nm}$ in the void volume and concentrated on an Amicon cell with PM-10 membrane to $300 \mu \mathrm{L}$. The protein concentration was measured using the BCA kit. Concentration of FITC was determined by spectrophotometry assuming the molar extinction coefficient of FITC epsilon $498=68,000 \mathrm{M}-1 \bullet \mathrm{cm}-1$. The protein/FITC ratio was 1: 1.4 .

2) Cell cultivation: Breast adenocarcinoma cells MCF-7 were cultured in plastic bottles ("Corning-Costar", USA) in DMEM medium containing 10\% FBS (fetal bovine serum) and gentamicin $(50 \mu \mathrm{g} / \mathrm{ml})$ in incubator at $37{ }^{\circ} \mathrm{C}$ and humidified atmosphere containing $5 \% \mathrm{CO}_{2}$.

3) Flow cytometry: One day before the experiment, cells were transferred to 6-well plates ("Corning-Costar", USA). Before starting the experiment, cells were incubated for 2 hours in DMEM medium without FBS. To analyze the binding, AFP3D-FITC was added to a suspension of cells in the concentration range $30-4000 \mathrm{nM}$ and incubated at $4{ }^{\circ} \mathrm{C}$ for 1 hour. To analyze the endocytosis, incubation was performed at $37^{\circ} \mathrm{C}$, and then cells were washed three times with cold PBS and fixed with $2 \%$ paraformaldehyde (PF) in PBS. Fluorescence intensity was measured using an EPICS-C flow cytofluorometer ("Coulter Electronics", USA). Fluorescence was excited by an argon laser (wavelength $488 \mathrm{~nm}$, emission bandwidth $520 \mathrm{~nm}$ ). For every sample $\left(10^{\wedge} 5\right.$ cells) the median fluorescence intensity (MFI) and percentage of cells that exceeded the fluorescence of autofluorescence were determined. The specificity of AFP3DFITC binding to AFP receptor was determined by incubating the cells with AFP3D-FITC in the presence of a 30-fold excess of AFP.

\subsection{Conjugation of AFP3D with PAMAM Dendrimer and Doxorubicin}

1) Conjugation in the aqueous medium: $172 \mathrm{mg}$ of a condensing agent, EDC (1-Ethyl-3-[3-dimethylaminopropyl] carbodiimide hydrochloride) was dissolved in $3 \mathrm{ml}$ of PBS to obtain a concentration of $0.3 \mathrm{M}$ (buffer A). To this buffer $3 \mathrm{mg}$ of dendrimer PAMAM-COOH $3.5 \mathrm{G}$ (37 ml of $10 \%$ methanol solution) was added and solution was stirred for $30 \mathrm{~min}$ at room temperature. Sulfo-NHS (Sulfo-N-hydroxysuccinimide) was added in catalytic amounts. Protein solution, concentrated to 4 $\mathrm{mg}$ in $500 \mathrm{ml}$, was then added dropwise, with constant stirring. After $10 \mathrm{~min}$ of incubation at room temperature, $2 \mathrm{~mL}$ of doxorubicin (Dox) with a concentration of $1 \mathrm{mg} / \mathrm{ml}$ and buffer A up to concentration of $0.2 \mathrm{M}$ EDC were added. The mixture was incubated for 1 hour at room temperature with stirring.

2) Conjugation in non-aqueous medium: To PAMAM dendrimer $(1.8 \mathrm{mg}$ ), dissolved in $500 \mathrm{~mL}$ of DMFA (dimethylformamide) with $10 \%$ of D-MAP (dimethylaminopyridine), a 14-fold excess of EDC (1 mg) was added. Mixture was incubated for $30 \mathrm{~min}$ at room temperature. Then catalytic amounts of the Sulfo-NHS and $2 \mathrm{mg}$ of AFP3D concentrated in $500 \mathrm{~mL}$ were added. Then $4 \mathrm{~mL}$ of $0.1 \%$ doxorubicin solution was added dropwise. The mixture was incubated for 2 hours with stirring. The solution was clarified by centrifugation. Unbound doxorubicin and dendrimer were removed by dialysis against 3 L of buffer $0.05 \mathrm{M} \mathrm{NaHCO3,} \mathrm{pH} \mathrm{8.7,} \mathrm{for} 2$ days. Resulting solution was centrifuged at $14,000 \mathrm{rev} / \mathrm{min}$ for $30 \mathrm{~min}$ at $15^{\circ} \mathrm{C}$. Supernatant was collected, filtered through a sterilizing filter Chromafil-Pet-20/15 MS with a pore diameter of $0.20 \mu \mathrm{m}$ and frozen at $-70^{\circ} \mathrm{C}$.

\subsection{Determination of Antiproliferative Activity of AFP3D-PAMAM-Dox Using the MTT-test}

Breast carcinoma cells MCF-7 were cultured in plastic flasks in RPMI medium containing $10 \%$ of FBS, $100 \mathrm{u} / \mathrm{mL}$ penicillin and $100 \mu \mathrm{g} / \mathrm{mL}$ streptomycin in a humidified atmosphere of $5 \%$ $\mathrm{CO} 2$ at $37^{\circ} \mathrm{C}$. Cells were transferred into 96 -well plates by 10 000 cells per well. Conjugates being investigated were added at various concentrations and cells were incubated for $72 \mathrm{~h}$. Four hours before the incubation finish, $50 \mu \mathrm{L}$ of MTT solution at concentration of $1 \mathrm{mg} / \mathrm{mL}$ in the culture medium was added to each well. After color development, the medium was removed, the sedimented formazan crystals were dissolved in $150 \mu \mathrm{L}$ of DMSO, and the color intensity was measured by absorption at $540 \mathrm{~nm}$ on a plate spectrophotometer (Labsystem). The cell survivability was estimated as percentage of untreated control. 


\section{Results}

\subsection{Expression of AFP3D in E. Coli}

Polyacrylamide gel electrophoresis (PAGE) confirmed that the target protein is synthesized in high yield and accumulated in inclusion bodies (Figure 1).

\subsection{Biological Activity of Recombinant AFP3D}

To determine the biological activity of obtained recombinant AFP3D, we examined the binding at $4^{\circ} \mathrm{C}$ and endocytosis at $37^{\circ} \mathrm{C}$ of FITC-labeled AFP3D by MCF-7 human breast cancer cells using flow cytofluometry. To study the binding, the cells were incubated with AFP3D-FITC at $+4{ }^{\circ} \mathrm{C}$ for one hour, washed, fixed, and then the fluorescence of the cells was measured. It was shown that AFP3D-FITC binds to MCF-7 cells. To investigate the specificity of binding, MCF-7 cells were incubated with AFP3D-FITC in the presence of a 30-fold excess of human AFP for one hour at $+4{ }^{\circ} \mathrm{C}$. Incubation of MCF-7 under these conditions led to a significant reduction of AFP3D-FITC binding to tumor cells (Figure 2). To study the endocytosis, MCF-7 cells were incubated with AFP3D-FITC for one hour at $+37^{\circ} \mathrm{C}$. AFP3D binding to tumor cells correlates with endocytosis (Figure 3), which means that these processes are interrelated.

\subsection{The Component Ratio in the Resulting Conjugates}

The protein concentration was measured using the BCA kit. Concentration of doxorubicin was determined by spectrophotometric method. In the conjugate synthesized in aqueous media, the protein: cytostatic ratio was 1 : 3.5, i.e. one molecule of the recombinant protein was associated with dendrimer carrying 3.5 molecules of doxorubicin. In the conjugate synthesized in nonaqueous media, the protein : cytostatic ratio was $1: 7.9$.

\subsection{Cytotoxic Activity of AFP3D-PAMAM-Dox Conjugates}

To determinate the cytotoxic activity of conjugates, we examined their ability to influence survival of human breast carcinoma cell line MCF-7. Tumor cells were incubated with conjugates for 72 hours. The data shown in Figure 4 demonstrates

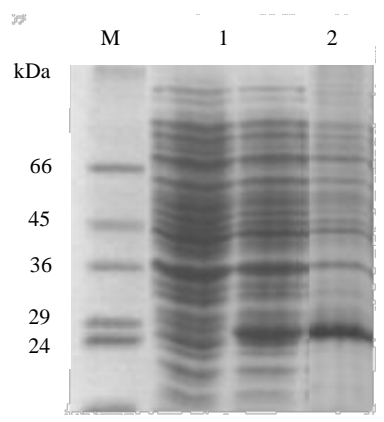

Figure 1. AFP3D gene expression. The results of electrophoresis in $13 \%$ polyacrylamide gel in the presence of SDS. Total cell proteins of E.coli, transformed with plasmid pAFP28D3: before the induction (1), after the induction with IPTG (2), inclusion bodies (3), M-molecular weight markers.

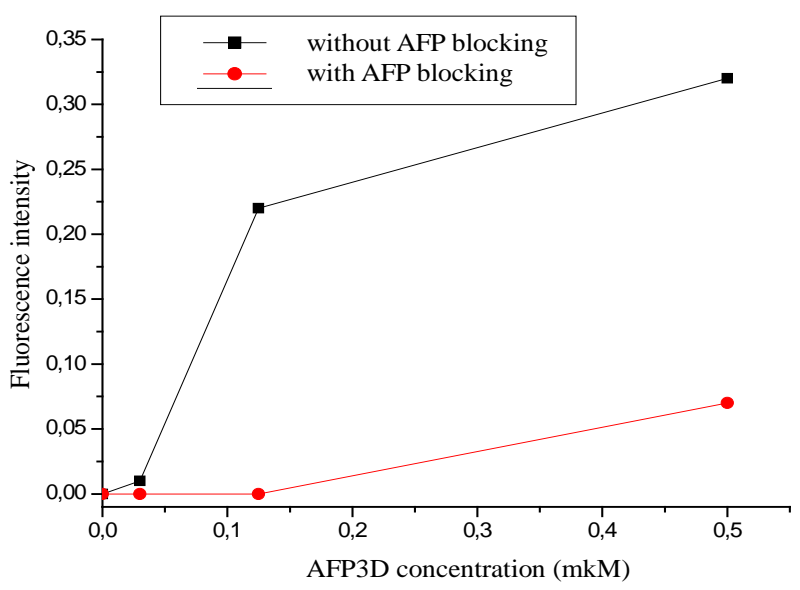

Figure 2. 30-fold excess of AFP inhibits binding of AFP3D-FITC to MCF-7 cells.

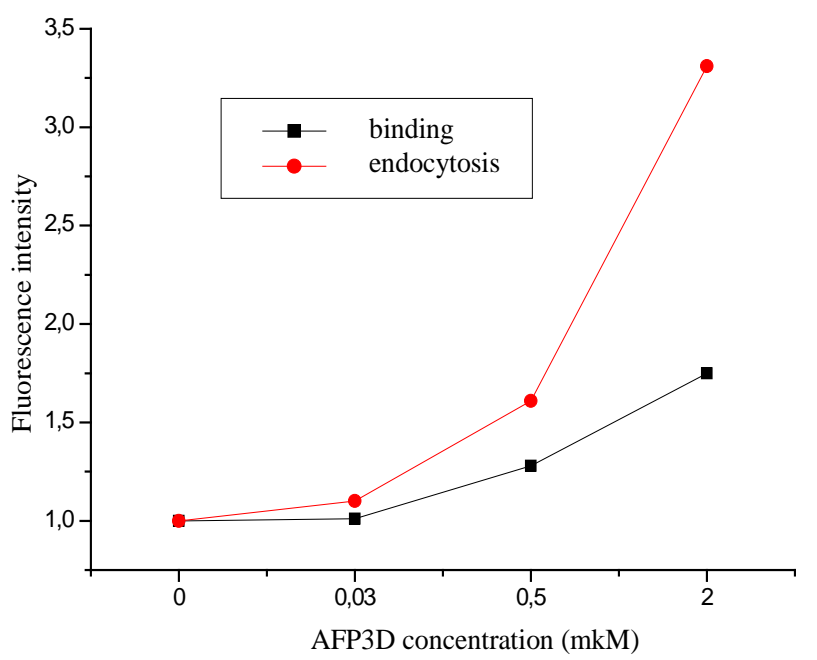

Figure 3. Correlation between binding and endocytosis of AFP3DFITC by MCF-7 cells.

that both of the conjugates decreased survival of tumor cells, and the inhibitory effect was dose-dependent. The inhibitory effect of the conjugate, obtained in non-aqueous conditions, was higher than inhibitory effect of the aqueous-synthesized compound, but lower than that of pure doxorubicin.

\section{Discussion}

In this study, we have synthesized an AFP3D conjugate with doxorubicin-loaded PAMAM dendrimer nanoparticles and investigated its cytotoxic activity.

To produce the recombinant AFP3D, E. coli strain, containing plasmid pAFP28D3, was used. The final yield of highly purified AFP3D, obtained by this method, is $23 \mathrm{mg}$ per liter of bacterial culture, which is a sufficient quantity for preparative use.

The excess of native AFP suppressed AFP3D binding to tumor cells, which shows that recombinant AFP3D competes with native AFP for binding to the specific AFP receptor. Correlation between AFP3D binding and endocytosis shows that endocytosis is receptor-mediated. Thus, AFP3D obtained by this method could be used as vector molecule. 


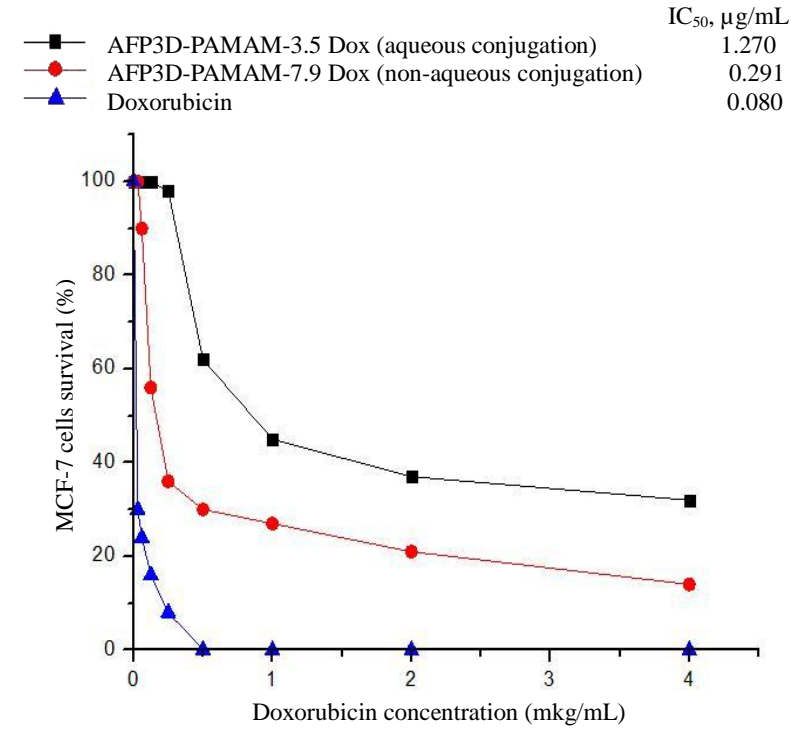

Figure 4. The cytotoxic activity of conjugates AFP3D-PAMAMDox against breast cancer cell line MCF-7.

To carry out conjugation reactions the water-soluble carbodiimide was used. EDC was chosen as cross-linking agent because of its ability to form a direct covalent amide bond between two molecules without additional atoms. That prevents the possibility of immune response and formation of antibodies specific to the linker. Non-aqueous conjugation was carried in a polar aprotonic solvent DMFA with the addition of DMAP as a nucleophilic catalyst.

Our experiments have shown that the conjugation carried in non-aqueous medium is more than twice efficient then the conjugation carried in water. In the conjugate synthesized in non-aqueous reaction, the AFP3D : doxorubicin ratio was 1:7.9, while the ratio obtained in aqueous reaction was 1:3.5.

Both drugs showed dose-related cytotoxic activity (CTA) against tumor cells. CTA level of the conjugate, obtained in non-aqueous medium, was higher than that of the conjugate, obtained in aqueous medium, but lower than CTA of pure doxorubicin. These results propose that higher load of conjugate with doxorubicin increases it's CTA. Lower CTA of conjugates than pure doxorubicin's one is due to difficult dissociation of doxorubicin from the dendrimer within the cell.

It should be noted that in vivo anti-tumor drug compounds (including doxorubicin) easily penetrate not only the tumor, but also all types of normal cells, causing different side effects. The presented results indicate that the AFP3D-PAMAM-Dox conjugate has directed action on the cells of malignant tumors. Therefore, despite the lower values of conjugates' CTA compared with the CTA of free doxorubicin in vitro, the therapeutic use of the conjugates in vivo can possibly minimize the negative side effects of antitumor drugs alone. This approach allows increasing the dosage of the drug, as well as improves the safety of anticancer therapy.

\section{REFERENCES}

[1] B.F.Crandall, Alpha-fetoprotein, CRC Rev. Clin. Lab. Sci., vol. 15, pp. 127-185, 1981.

[2] R. Chaturvedi, V. Agarkar, G. L. Sharma, P.U. Sarma, Purification of alpha-fetoprotein from human cord blood, Prep. Biochem. Biotechnol., pp. 293-303, April 1998.

[3] H. F. Deutsch, Chemisry and Biology of $\alpha$-fetoprotein, Adv. Cancer Res., vol.56, 1991, pp. 253-312.

[4] S. Nishi, H. Hirai, Purification of human, dog and rabbit $\alpha$-fetoprotein by immunoadsorbents of Sepharose coupled with anti-human $\alpha$-fetoprotein, Biochim. Biophys. Acta, vol. 278, pp. 293-298, 1972.

[5] R. Boismenu, D. Semeniuk, R. A. Murgita, Purification and characterization of human and mouse recombinant alpha-fetoproteins expressed in Escherichia coli, Protein Expression and Purif., vol. 10, pp.10-26, 1997.

[6] Posypanova G. A., Gorokhovets N. V., Makarov V. A., Savvateeva L. V., Kireeva N. N., Severin S. E., Severin E. S., Recombinant alpha-fetoprotein C-terminal fragment: the new recombinant vector for targeted delivery. J Drug Target., vol.16, pp. 321-328, May 2008.

[7] Savvateeva L. V., Gorokhovets N. V., Makarov V. A., Posypanova G. A., Severin S. E., Recombinant third domain of human alpha-fetoprotein: selectivity and antitumor activity of conjugate with Taxol. Abstracts of the XXXIII Meeting of the International Society for Oncodevelopmental Biology and Medicine (ISOBM), Rhodes, Greece, p. 84., September 2005. 